\title{
GMR
}

\section{Development of a polymorphic short tandem repeat locus multiplex system for efficient human identification}

\author{
R.G. Rodovalho ${ }^{1,2}$, E.L. Rodrigues ${ }^{7}$, G.S. Santos ${ }^{2}$, L.M. Cavalcanti ${ }^{2}$, \\ P.R. Lima ${ }^{2}$, A.G. Rodovalho ${ }^{3}$, R.G. Vital ${ }^{4}$, M.A.D. Gigonzac ${ }^{1,5,6}$ and \\ A.D. da Cruz ${ }^{1,5,6}$ \\ ${ }^{1}$ Programa de Pós-Graduação em Biotecnologia e Biodiversidade, \\ Rede Pró Centro-Oeste, Goiânia, GO, Brasil \\ ${ }^{2}$ Laboratório Biocroma - Clínica de Exames de DNA, Goiânia, GO, Brasil \\ ${ }^{3}$ Programa de Pos-Graduação em Gestão Organizacional - Mestrado Profissional, \\ Universidade Federal de Goiás, Catalão, GO, Brasil \\ ${ }^{4}$ Instituto Federal de Educação, Ciência e Tecnologia Goiano, \\ Campus Rio Verde, Rio Verde, GO, Brasil \\ ${ }^{5}$ Departamento de Biologia, Núcleo de Pesquisas Replicon, \\ Pontifícia Universidade Católica de Goiás, Goiânia, GO, Brasil \\ ${ }^{6}$ Laboratório de Citogenética Humana e Biologia Molecular, \\ Secretaria Estadual de Saúde, Goiânia, GO, Brasil \\ ${ }^{7}$ Promega Corporation, Departamento de Identificação Humana, \\ São Paulo, SP, Brasil \\ Corresponding author: R.G. Rodovalho \\ E-mail: ricardogrodovalho@hotmail.com
}

Genet. Mol. Res. 16 (2): gmr16029557

Received November 29, 2016

Accepted March 8, 2017

Published April 5, 2017

DOI http://dx.doi.org/10.4238/gmr16029557

Copyright (C) 2017 The Authors. This is an open-access article distributed under the terms of the Creative Commons Attribution ShareAlike (CC BY-SA) 4.0 License.

ABSTRACT. This study aimed to develop a short tandem repeat (STR) multiplex system, made up of 22 highly informative STR loci, for application in forensic genetics. The system comprised 21 polymorphic autosomal loci (D3S1358, TH01, D21S11, D18S51, Penta E, D5S818,

Genetics and Molecular Research 16 (2): gmr16029557 
D13S317, D7S820, D16S539, CSF1PO, Penta D, vWA, D8S1179, TPOX, FGA, D2S441, D17S1301, D19S433, D18S853, D20S482, and D14S1434) and the amelogenin gene locus. Strategies were developed to overcome the challenges involved in creating a multiplex system. Based on the literature and available databases, the STR loci were selected with the aim to obtain discriminatory markers, and followed specific criteria for this purpose. Primers were projected using the Primer3 software, and AutoDimer was used to evaluate possible interactions between them. The 22 selected STR loci were validated individually and jointly, both to assess their sensitivity and to test the efficiency of the multiplex system. Statistical analyses were based on the genetic data of 450 unrelated individuals living in the State of Goiás, thus allowing the establishment of the parameters necessary to use this system. A total of 239 alleles were detected for the 22 loci in the set, allowing for a probability of identity of $4.23 \times 10^{-25}$ to be obtained. The combined power of discrimination was 0.999999999999999999999999 and the combined power of exclusion was 0.99999. Upon complete validation of the entire system, this multiplex assay was considered to be a powerful tool for application in human identification by DNA analysis.

Key words: Human identification; Microsatellites; Paternity; Multiplex; Allele frequency

\section{INTRODUCTION}

The advance of biotechnology-related techniques has allowed the proposal of new strategies for identifying the genetic profile of each person, the tools for which have become quite revolutionary in the practice of individual identification using human molecular genetics (Brevnov et al., 2009; Budowle and van Daal, 2009; Mattana et al., 2012).

According to Sarmento (2006), human identification by DNA analysis may be a helpful tool for the disclosure of guilty criminals and innocent defendants, the identification of bodies and human remains in mass disasters, the determination of parental linkage, and the detection of technical mistakes attributed to labeling errors in clinical pathology laboratories (Ruitberg et al., 2001; Buckleton et al., 2004).

The development of short tandem repeat (STR) multiplex systems with simultaneous amplification has ensured facilities for human identification with an excellent power of discrimination, low consumption of biological samples and inputs, and high practicality in technical routine. As such, the application of multiplex systems to analyze samples has resulted in the acquisition of complete genetic profiles that can be compared and discriminated (Butler, 2006; Zhang et al., 2015).

The ability to analyze multiple-STRs simultaneously, together with multicolor fluorescence detection technologies, has greatly contributed to the consolidation of these important technical principles for the science of determining genetic identity (Buckleton et al., 2004; Hill et al., 2008; Wang et al., 2011). The 13 STR loci that initially comprised the Combined DNA Index System (CODIS) were made extensively available in commercial kits (Opel et al., 2007), and the same panel was soon further expanded to 20 loci (Hares, 2012,

Genetics and Molecular Research 16 (2): gmr16029557 
2015). Meanwhile, several other highly polymorphic STR loci, neither a subset of CODIS nor commercially available, were capable of considerably raising the power of discrimination in analysis (Opel et al., 2007; Hill et al., 2009).

According to Wiegand et al. (2006), several real situations of high analytical complexity require a molecular arsenal focused on the power of individual discrimination. In these situations, the application of methods that increase the power of discrimination corroborates the issuance of conclusive opinions. On the other hand, the unavailability of these resources prompts the unfeasibility of analysis (Gill et al., 1991, 2006).

In this sense, Poetsch et al. (2013) concluded that the number of hypervariable loci available for a genetic linkage analysis is directly associated with the percentage of certainty established during the assessment of the analysis (Børsting et al., 2008; Rodovalho et al., 2015; Zhang et al., 2015). Therefore, it is critical that STR panels provide sufficient security, permitting an accurate and unfailing conclusion regarding the genetic linkage analysis. However, both a very close correlation between the quantity and quality of the polymorphic loci present in an STR system, and the degree of accuracy of the methodology, are evident. Thus, the greater the number of STRs analyzed, the greater would be the resolving power of the study (Wiegand et al., 2006).

This study aimed to develop a new STR multiplex system comprising CODIS and non-CODIS highly polymorphic loci for simultaneous analysis, and to assess its efficiency for forensic application. The loci introduced into the system are distinguished from commercial systems, to allow the introduction of new markers in complex genetic analyses that require complementation. Thus, this panel comprised 18 loci commonly present in commercial systems, allowing for the complementary analysis required in situations that include null alleles.

\section{MATERIAL AND METHODS}

\section{Selection of the STR loci}

This study selected 22 STR loci coupled with the layout of the desired multiplex project, based on literature reviews from the National Center for Biotechnology Information (NCBI; http://www.ncbi.nlm.nih.gov) and STRBase (National Institute of Standards and Technology, Chemical Science \& Technology Laboratory; http://www.cstl.nist.gov/strbase/), with the following criteria: location on different chromosomes (physical distance of at least 10 $\mathrm{Mb}$ from another locus if on the same chromosome), power of discrimination, allelic diversity, amplicons size, and presence in compatible databases.

\section{Obtaining sequencing primers}

The sequencing primers for the selected loci were obtained using the online Primer3 software (http://bioinfo.ut.ee/primer3-0.4.0/) (Rozen and Skaletsky, 2000), so that the size of the amplified products would be within the range established for the entire planned system. Then, the AutoDimer software (https://www-s.nist.gov/dnaAnalysis/) (Vallone and Butler, 2004) was used to assess sequences that could potentially self-anneal to form primer dimers, an event known as hairpin formation. Genome alignment analysis was performed using Primer-BLAST (http://www.ncbi.nlm.nih.gov/tools/primer-blast/), an NCBI tool used to identify locations in the genome where spurious annealing may occur beyond the target DNA.

Genetics and Molecular Research 16 (2): gmr16029557 


\section{Obtaining primers and developing the multiplex assay}

The allelic variations for each STR locus were analyzed on the basis of literature reviews related to the dimensions that each molecular marker may take because of insertions of rare alleles, which are at the ends of the STR locus. These precautions were taken to avoid possible overlaps between neighboring loci and components of the same fluorescence channels.

The locus organization in the panel was designed by considering the schematic multiplex arrangement with the candidate positions for each locus. The architecture of the system layout allowed for estimation of the spacing between the loci and calculation of the size required for each PCR product according to its reference sequence.

All primers were synthesized by Applied Biosystems (Foster City, CA, USA), and the forward sequence of each STR was labeled with one of the following dye sets: 6-FAM ${ }^{\mathrm{TM}}$, $\mathrm{VIC}^{\circledR}, \mathrm{NED}^{\mathrm{TM}}$, and $\mathrm{PET}^{\circledR}$ (Applied Biosystems), as shown in Table 1.

\section{Amplification using PCR and detection of genetic profiles}

The PCRs for all the developed STRs were performed in singleplex assays to assess the behavior of the primer and ensure that the amplicon corresponded to the expected size. Upon validation of all the individual STRs, amplification in a single-multiplex PCR was carried out. For this, a primer mix was prepared according to the individual concentrations of each primer, established on the basis of the joint amplification signal strength. For the multiplex PCR, a Qiagen ${ }^{\circledR}$ Multiplex PCR Kit (Qiagen, Hilden, Germany) was used together with the primer mix and $5.0 \mathrm{ng}$ genomic DNA, in a final reaction volume of $25 \mu \mathrm{L}$. The thermocycling conditions were as follows: an initial incubation at $95^{\circ} \mathrm{C}$ for $5 \mathrm{~min} ; 30$ cycles of $94^{\circ} \mathrm{C}$ for $30 \mathrm{~s}$, $60^{\circ} \mathrm{C}$ for $90 \mathrm{~s}$, and $72^{\circ} \mathrm{C}$ for $60 \mathrm{~s}$; and a final extension at $60^{\circ} \mathrm{C}$ for $30 \mathrm{~min}$.

Capillary electrophoresis of the PCR products preceded the preparation step with $1 \mu \mathrm{L}$ of amplified product, $8.5 \mu \mathrm{L}$ Hi-Di ${ }^{\mathrm{TM}}$ formamide (Applied Biosystems), and $0.5 \mu \mathrm{L}$ GeneScan $^{\mathrm{TM}}$ - 600 LIZ $^{\circledR}$ Size Standard v2.0 (Applied Biosystems). The separation and detection of fragments were performed with the ABI 3500 Genetic Analyzer (Applied Biosystems) using POP4 (Applied Biosystems). The samples were injected electrokinetically at $1.2 \mathrm{kV}$ for $15 \mathrm{~s}$. The electrophoresis run time for allele separation was $1210 \mathrm{~s}$ at $15 \mathrm{kV}$ and $60^{\circ} \mathrm{C}$. The allelic fragments obtained were analyzed with GeneMapper ${ }^{\mathbb{}}$ ID-X version 1.2 (Applied Biosystems). The overall performance of the multiplex system was assessed using the 2800M-positive control DNA (Promega Corporation, Madison, WI, USA).

\section{Sensitivity and concordance test}

The sensitivity of the multiplex system was assessed by decreasing the amount (10, 5, 3, 1, and 0.5 ng) of the 2800M-positive control DNA (Promega Corporation) in the PCR. The sensitivity limit was based on the amplification having at least 80 relative fluorescence units (RFU). The DNA from blood samples, buccal swabs, and hair was extracted using the QIAamp ${ }^{\circledR}$ DNA Investigator Kit (Qiagen), and amplified to assess the sensitivity and efficiency of the multiplex for different samples. The direct amplification from blood samples was also assessed for the developed multiplex using the Whatman ${ }^{\circledR}$ FTA $^{\circledR}$ card.

The PowerPlex ${ }^{\circledR}$ Fusion System (Promega Corporation) was used to perform concordance tests between the common loci in the two systems (D3S1358, TH01, D21S11,

Genetics and Molecular Research 16 (2): gmr16029557 
D18S51, Penta E, D5S818, D13S317, D7S820, D16S539, CSF1PO, Penta D, amelogenin, vWA, D8S1179, TPOX, FGA, D2S441, and D19S433). The other non-coincident loci (D17S1301, D18S853, D20S482, and D14S1434) were not assessed, because they were not present in any kit currently commercially available in Brazil.

\section{Population analysis of STR polymorphism}

Peripheral blood was collected by digital puncture from 450 unrelated individuals living in the State of Goiás, Brazil. The blood was impregnated on Whatman ${ }^{\circledR}$ FTA $^{\circledR}$ cards for further amplification with the newly developed multiplex set and the PowerPlex ${ }^{\circledR}$ Fusion System.

The collection of biological material began after the Research Ethics Committee of the Pontifical Catholic University of Goiás had approved the research (CAAE: 51483415.9.0000.0037 and opinion number 1.721.890).

\section{Statistical analyses}

The statistical parameters for the allele frequencies were obtained using Genetix version 4.05 and PowerStats softwares (Tereba, 1999; Belkhir et al., 2004; da Costa Francez et al., 2011). The alleles were tested for Hardy-Weinberg equilibrium using Genepop version 4.1.4 and Arlequin version 3.1 softwares (Excoffier et al., 2007; da Costa Francez et al., 2011). Other statistical parameters associated with the study population, such as the probability of identity, power of discrimination, polymorphism information content, power of exclusion, and typical paternity index, were calculated using PowerStats (Tereba, 1999).

\section{RESULTS AND DISCUSSION}

Following the criteria for selecting STRs, 22 polymorphic loci were selected to make up the multiplex panel (Table 1). Of these 22 loci, only TPOX and D2S441 (chromosome 2), D5S818 and CSF1PO (chromosome 5), D18S51 and D18S853 (chromosome 18), and D21S11 and Penta D (chromosome 21) were located on the same chromosome, at a minimum distance of $10 \mathrm{Mb}$. The developed multiplex set comprised 15 CODIS loci and 6 non-CODIS loci (Penta E, Penta D, D17S1301, D18S853, D20S482, and D14S1434).

To assess the performance of the synthesized primers and identify the annealing temperature common to all of them, the STRs were first assessed individually. Since no locus presented amplification failure and/or artifact excess that could compromise the yield expected for the system, the primers were subsequently combined in a multiplex reaction. As expected, the preliminary tests of the multiplex combination showed a large imbalance between the involved primers, probably due to some factors that interfered with the reaction, such as different annealing temperatures. To balance the combined primers, the amplification intensity was assessed individually to adjust their specific concentrations, assigning higher concentrations to the primers that obtained lower yield and, conversely, lower concentrations for the primers that showed allelic peaks with high RFU. The fluorescence labels, specific concentrations of each primer, and other information pertinent to the loci included in the multiplex are described in Table 1.

After optimization of the PCR in the multiplex system, the set of selected primers was successfully amplified in a single reaction, obtaining a harmonic and noise-free final panel. Figure 1 shows the allelic profile obtained for the $2800 \mathrm{M}$-positive control DNA.

Genetics and Molecular Research 16 (2): gmr16029557 
Table 1. Data for the short tandem repeat loci present in the developed multiplex system.

\begin{tabular}{|c|c|c|c|c|c|}
\hline Dye label & Locus & Chromosomal location & Repeat unit & Primer concentration $(\mu \mathrm{M})$ & Fragment size range (bp) \\
\hline $\mathrm{M}^{\mathrm{TM}}$ & D3S1358 & $3 \mathrm{p} 21.31$ & TCTG/TCTA & 0.10 & $91-143$ \\
\hline 6-FAM ${ }^{\mathrm{TM}}$ & TH01 & $11 \mathrm{p} 15.5$ & AATG & 0.20 & $156-205$ \\
\hline $6-\mathrm{FAM}^{\mathrm{TM}}$ & D21S11 & $21 \mathrm{q} 21.1$ & TCTA/TCTG & 0.30 & $215-271$ \\
\hline 6-FAM ${ }^{\mathrm{TM}}$ & D18S51 & $18 \mathrm{q} 21.33$ & AGAA & 0.20 & $282-362$ \\
\hline $6-\mathrm{FAM}^{\mathrm{TM}}$ & Penta E & $15 \mathrm{q} 26.2$ & AAAGA & 0.20 & $369-494$ \\
\hline $\mathrm{VIC}^{\circledR}$ & D5S818 & $5 \mathrm{q} 23.2$ & AGAT & 0.20 & $111-155$ \\
\hline $\mathrm{VIC}^{\circledR}$ & D13S317 & $13 \mathrm{q} 31.1$ & TATC & 0.10 & 164-204 \\
\hline $\mathrm{VIC}^{\circledR}$ & D7S820 & $7 \mathrm{q} 21.11$ & GATA & 0.20 & $215-259$ \\
\hline $\mathrm{VIC}^{\circledR}$ & D16S539 & $16 \mathrm{q} 24.1$ & GATA & 0.25 & $268-312$ \\
\hline $\mathrm{VIC}^{\circledR}$ & CSF1PO & $5 \mathrm{q} 33.1$ & AGAT & 0.15 & $321-369$ \\
\hline $\mathrm{VIC}^{\circledR}$ & Penta D & $21 \mathrm{q} 22.3$ & AAAGA & 0.30 & $381-489$ \\
\hline $\mathrm{NED}^{\mathrm{TM}}$ & Amelogenin & $\mathrm{Xp} 22.1-22.3$ and $\mathrm{Y}$ & - & 0.10 & $106-112$ \\
\hline $\mathrm{NED}^{\mathrm{TM}}$ & vWA & $12 \mathrm{p} 13.31$ & TCTG/TCTA & 0.20 & $115-183$ \\
\hline $\mathrm{NED}^{\mathrm{TM}}$ & D8S1179 & $8 \mathrm{q} 24.13$ & TCTA/TCTG & 0.50 & $195-251$ \\
\hline $\mathrm{NED}^{\mathrm{TM}}$ & TPOX & $2 \mathrm{p} 25.3$ & AATG & 0.08 & $258-302$ \\
\hline $\mathrm{NED}^{\mathrm{TM}}$ & FGA & $4 \mathrm{q} 31.3$ & TTTC & 0.15 & $314-444$ \\
\hline $\mathrm{PET}^{\circledR}$ & D2S441 & $2 \mathrm{p} 14$ & TCTA & 0.15 & $78-106$ \\
\hline $\mathrm{PET}^{\mathbb{B}}$ & $\mathrm{D} 17 \mathrm{~S} 1301$ & $17 \mathrm{q} 25.1$ & AGAT & 0.50 & $110-150$ \\
\hline $\mathrm{PET}^{\circledR}$ & D19S433 & $19 \mathrm{q} 12$ & AAGG & 0.25 & $184-212$ \\
\hline $\mathrm{PET}^{\mathbb{B}}$ & D18S853 & $18 \mathrm{p} 11.31$ & ATA & 0.40 & $215-242$ \\
\hline $\mathrm{PET}^{\circledR}$ & D20S482 & $20 \mathrm{p} 13$ & AGAT & 0.15 & $259-311$ \\
\hline $\mathrm{PET}^{\circledR}$ & D14S1434 & $14 q 32.13$ & CTGT/CTAT & 0.20 & $321-369$ \\
\hline
\end{tabular}
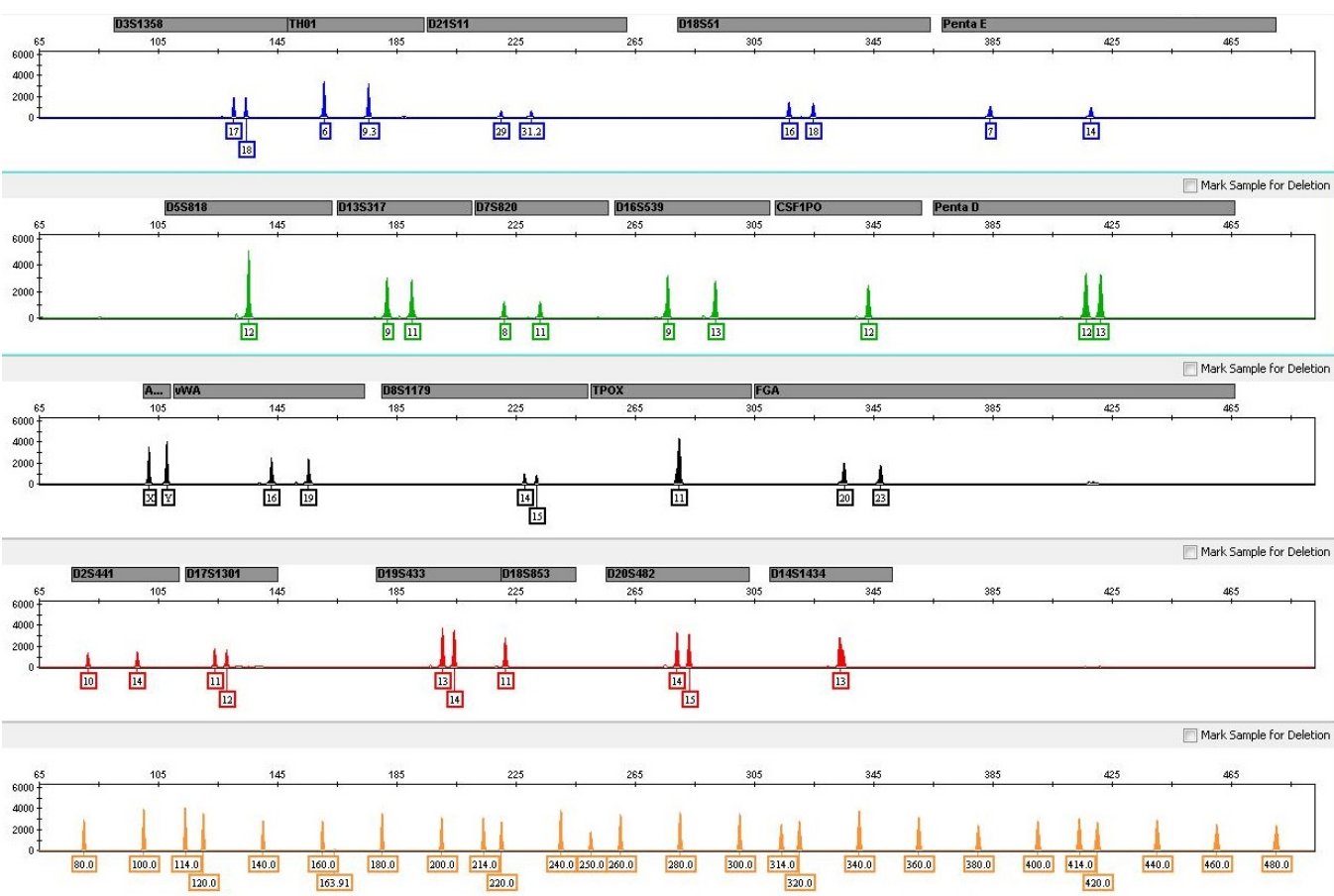

Figure 1. Genetic profile of the 2800M-positive control DNA obtained with the newly developed multiplex system.

Genetics and Molecular Research 16 (2): gmr16029557 
The multiplex amplification assessment of the different concentrations of the 2800M-positive control DNA showed 100\% allelic identity in the reactions with DNA ranging from 1 to $10 \mathrm{ng}$. However, DNA at the concentration of $0.5 \mathrm{ng}$ did not present complete amplification for some loci in the system, revealing an incomplete genotypic profile with approximately $90 \%$ allelic identity. Direct amplification of blood samples impregnated on FTA $^{\circledR}$ cards and of DNA extracted from peripheral blood, buccal swab, and hair samples showed $100 \%$ allelic identity for all samples tested.

A comparison of the allelic profiles obtained by direct amplification of the 450 blood samples impregnated on FTA $^{\circledR}$ cards, using both the newly developed multiplex system and the PowerPlex ${ }^{\circledR}$ Fusion System, showed genotype matching for all loci analyzed.

The allelic frequencies and statistical parameters related to the genetic and forensic linkage analysis, obtained for the 21 autosomal multiplex loci for the population of the State of Goiás, Brazil, are described in Table $\mathbf{S 1}$ and Table 2, respectively.

Table 2. Statistical parameters of autosomal multiplex loci for the population of the State of Goiás, Brazil.

\begin{tabular}{l|c|c|c|c|c|c|c}
\hline Locus & \%Hets & MP & PD & PIC & PE & TPI & N \\
\hline D3S1358 & 80.9 & 0.104 & 0.896 & 0.73 & 0.616 & 2.62 & 450 \\
\hline TH01 & 80.2 & 0.077 & 0.923 & 0.76 & 0.603 & 2.53 & 450 \\
\hline D21S11 & 87.1 & 0.047 & 0.953 & 0.82 & 0.737 & 3.88 & 450 \\
\hline D18S51 & 87.8 & 0.026 & 0.974 & 0.87 & 0.750 & 4.09 & 450 \\
\hline Penta E & 90.7 & 0.019 & 0.981 & 0.90 & 0.809 & 5.36 & 450 \\
\hline D5S818 & 74.0 & 0.115 & 0.885 & 0.69 & 0.493 & 1.92 & 450 \\
\hline D13S317 & 76.0 & 0.075 & 0.925 & 0.76 & 0.527 & 2.08 & 450 \\
\hline D1S820 & 77.8 & 0.075 & 0.925 & 0.76 & 0.558 & 2.25 & 450 \\
\hline CSF1PO & 79.8 & 0.077 & 0.923 & 0.76 & 0.595 & 2.47 & 450 \\
\hline Penta D & 70.4 & 0.111 & 0.889 & 0.69 & 0.435 & 1.69 & 450 \\
\hline vWA & 85.8 & 0.035 & 0.965 & 0.85 & 0,710 & 3.52 & 450 \\
\hline D8S1179 & 77.8 & 0.072 & 0.928 & 0.77 & 0.558 & 2.25 & 450 \\
\hline TPOX & 67.4 & 0.063 & 0.937 & 0.78 & 0,570 & 2.32 & 450 \\
\hline FGA & 88.2 & 0.143 & 0.857 & 0.65 & 0.388 & 1.53 & 450 \\
\hline D2S441 & 76.4 & 0.085 & 0.972 & 0.87 & 0.759 & 4.25 & 450 \\
\hline D17S1301 & 66.2 & 0.166 & 0.915 & 0.74 & 0.535 & 2.12 & 450 \\
\hline D18S853 & 79.3 & 0.050 & 0.950 & 0.62 & 0.372 & 1.48 & 450 \\
\hline D20S482 & 74.4 & 0.105 & 0.895 & 0.70 & 0.500 & 1.96 & 4.62 \\
\hline D14S1434 & 69.1 & 0.146 & 0.854 & 0.64 & 0.415 & 450 \\
\hline
\end{tabular}

\%Hets: percentage heterozygosity; MP: match probability; PD: power of discrimination; PIC: polymorphism information content; PE: power of exclusion; TPI: typical paternity index; N: study population.

In general, the multiplex system showed large allelic variations, ranging from 7 alleles (TH01, D13S317, and D17S1301) to 24 (FGA), and a total of 239 alleles for the whole set. Deviation from Hardy-Weinberg equilibrium was observed for TPOX $(\mathrm{P}=0.01016)$, D17S1301 $(\mathrm{P}=0.00319)$, and $\mathrm{D} 14 \mathrm{~S} 1434(\mathrm{P}=0.03695)$. According to Hardy $(1908)$, this suggests that the population is under the influence of some factors, such as mutation rate, migration, selective pressure of the environment, or natural selection. By comparing the observed and expected heterozygosities, it was possible to find more homozygotes than expected. As such, amplification failure from a mutational event in the 3 ' region of the hybridization site of the primers had resulted in null alleles (Gomes et al., 1999; Dakin and Avise, 2004). Leibelt et al. (2003) described a mutation at the hybridization site in the D8S1179 locus in the population of Guam Island. Their study population demonstrated an excess of homozygotes at this locus when genotyped using AmpFISTR Profiler Plus ${ }^{\mathrm{TM}}$. Similar results were found by Budowle

Genetics and Molecular Research 16 (2): gmr16029557 
et al. (2000) in the population of Chamorros and Filipinos on the Island of Guam, and by Vanderheyden et al. (2007) in the population in Belga.

The statistical parameters obtained showed high values (Table 2). All loci showed high forensic efficiency, with the power of discrimination values being greater than 0.8 , ranging from 0.834 (D17S1301) to 0.981 (Penta E). The most polymorphic locus was Penta E, followed by the FGA and D18S51 loci. The polymorphism information content ranged from 0.62 (D17S1301) to 0.90 (Penta E). The combined power of discrimination for the 21 loci was 0.999999999999999999999999 , the combined power of exclusion was 0.99999 , and the identity power corresponded to $4.23 \times 10^{-25}$.

In conclusion, our STR multiplex system showed a high level of sensitivity, being capable of amplifying 21 autosomal loci and the amelogenin locus from several types of biological samples, including direct amplification on $\mathrm{FTA}^{\circledR}$, which incorporates versatility to the technical routine for obtaining a genetic profile. The high values found in the statistical parameters suggest that the developed multiplex system is highly polymorphic and informative, verifying that the set shows high discriminatory potential and therefore justifying its application in strategies involving human identification and genetic linkage analysis.

\section{Conflicts of interest}

The authors declare no conflicts of interest.

\section{ACKNOWLEDGMENTS}

The authors would like to thank the Biocroma Laboratory - DNA Testing Clinic, the Replicon/PUC-GO Research Center, and FAPEG for their comprehensive research support.

\section{REFERENCES}

Belkhir K, Borsa P, Chiki L, Raufaste N, et al. (2004). Genetix 4.05, logiciel sous Windows ${ }^{\mathrm{TM}}$ pour la génétique des populations. Laboratoire Génome, Populations, Interactions, CNRS UMR 5000. Université de Montpellier II, Montpellier. Available at [http://kimura.univ-montp2.fr/genetix/].

Børsting C, Sanchez JJ, Hansen HE, Hansen AJ, et al. (2008). Performance of the SNPforID 52 SNP-plex assay in paternity testing. Forensic Sci. Int. Genet. 2: 292-300. http://dx.doi.org/10.1016/j.fsigen.2008.03.007

Brevnov MG, Pawar HS, Mundt J, Calandro LM, et al. (2009). Developmental validation of the PrepFiler Forensic DNA Extraction Kit for extraction of genomic DNA from biological samples. J. Forensic Sci. 54: 599-607. http://dx.doi. org/10.1111/j.1556-4029.2009.01013.x

Buckleton JS, Triggs CM and Walsh SJ (2004). Forensic DNA evidence interpretation. CRC Press, Boca Raton.

Budowle B and van Daal A (2009). Extracting evidence from forensic DNA analyses: future molecular biology directions. Biotechniques 46: 339-340, 342-350. http://dx.doi.org/10.2144/000113136

Budowle B, Defenbaugh DA and Keys KM (2000). Genetic variation at nine short tandem repeat loci in Chamorros and Filipinos from Guam. Leg. Med. (Tokyo) 2: 26-30. http://dx.doi.org/10.1016/S1344-6223(00)80005-X

Butler JM (2006). Genetics and genomics of core short tandem repeat loci used in human identity testing. J. Forensic Sci. 51: 253-265. http://dx.doi.org/10.1111/j.1556-4029.2006.00046.x

da Costa Francez PA, Rodrigues EMR, Frazão GF, Dos Reis Borges ND, et al. (2011). Allelic frequencies and statistical data obtained from 12 codis STR loci in an admixed population of the Brazilian Amazon. Genet. Mol. Biol. 34: 35-39. http://dx.doi.org/10.1590/S1415-47572011000100007

Dakin EE and Avise JC (2004). Microsatellite null alleles in parentage analysis. Heredity (Edinb) 93: 504-509. http:// dx.doi.org/10.1038/sj.hdy. 6800545

Excoffier L, Laval G and Schneider S (2007). Arlequin (version 3.0): an integrated software package for population genetics data analysis. Evol. Bioinform. Online 1: 47-50.

Genetics and Molecular Research 16 (2): gmr16029557 
Gill P, Evett IW, Woodroffe S, Lygo JE, et al. (1991). Databases, quality control and interpretation of DNA profiling in the Home office Forensic Science Service. Electrophoresis 12: 204-209. http://dx.doi.org/10.1002/elps.1150120217

Gill P, Fereday L, Morling N and Schneider PM (2006). The evolution of DNA databases--recommendations for new European STR loci. Forensic Sci. Int. 156: 242-244. http://dx.doi.org/10.1016/j.forsciint.2005.05.036

Gomes I, Collins A, Lonjou C, Thomas NS, et al. (1999). Hardy-Weinberg quality control. Ann. Hum. Genet. 63: 535-538. http://dx.doi.org/10.1046/j.1469-1809.1999.6360535.x

Hardy GH (1908). Mendelian proportions in a mixed population. Science 28: 49-50. http://dx.doi.org/10.1126/ science.28.706.49

Hares DR (2012). Expanding the CODIS core loci in the United States. Forensic Sci. Int. Genet. 6: e52-e54. Erratum in Forensic Sci. Int. Genet. 6: e135.

Hares DR (2015). Selection and implementation of expanded CODIS core loci in the United States. Forensic Sci. Int. Genet. 17: 33-34. http://dx.doi.org/10.1016/j.fsigen.2015.03.006

Hill CR, Kline MC, Coble MD and Butler JM (2008). Characterization of 26 miniSTR loci for improved analysis of degraded DNA samples. J. Forensic Sci. 53: 73-80. http://dx.doi.org/10.1111/j.1556-4029.2008.00595.x

Hill CR, Butler JM and Vallone PM (2009). A 26plex autosomal STR assay to aid human identity testing. J. Forensic Sci. 54: 1008-1015. http://dx.doi.org/10.1111/j.1556-4029.2009.01110.x

Leibelt C, Budowle B, Collins P, Daoudi Y, et al. (2003). Identification of a D8S1179 primer binding site mutation and the validation of a primer designed to recover null alleles. Forensic Sci. Int. 133: 220-227. http://dx.doi.org/10.1016/ $\underline{\text { S0379-0738(03)00035-5 }}$

Mattana C, Fernandes MM, Tinoco R, Oliveira RN, et al. (2012). Forensic importance of DNA and the dentist participation. Braz. J. Forensic Sci. Med. Law Bioethics 2: 65-82. http://dx.doi.org/10.17063/bjfs2-1-y201265

Opel KL, Chung DT, Drábek J, Butler JM, et al. (2007). Developmental validation of reduced-size STR Miniplex primer sets. J. Forensic Sci. 52: 1263-1271. http://dx.doi.org/10.1111/j.1556-4029.2007.00584.x

Poetsch M, Preusse-Prange A, Schwark T and von Wurmb-Schwark N (2013). The new guidelines for paternity analysis in Germany-how many STR loci are necessary when investigating duo cases? Int. J. Legal Med. 127: 731-734. http:// dx.doi.org/10.1007/s00414-013-0867-y

Rodovalho RG, Santos GS, Cavalcanti LM, Moura BF, et al. (2015). Allele frequencies of combined DNA index system (CODIS) and non-CODIS short tandem repeat loci in Goiás, Central Brazil. Genet. Mol. Res. 14: 7310-7314. http:// dx.doi.org/10.4238/2015.July.3.6

Rozen S and Skaletsky H (2000). Primer3 on the WWW for general users and for biologist programmers. Methods Mol. Biol. 132: 365-386.

Ruitberg CM, Reeder DJ and Butler JM (2001). STRBase: a short tandem repeat DNA database for the human identity testing community. Nucleic Acids Res. 29: 320-322. http://dx.doi.org/10.1093/nar/29.1.320

Sarmento FJQ (2006). Modelagem de um ambiente para análise de DNA em genética forense. Dissertação de Mestrado, Universidade Federal de Alagoas, Campus Maceió, Maceió.

Tereba A (1999). Tools for analysis of population statistics. Profiles DNA 2: 14-16.

Vallone PM and Butler JM (2004). AutoDimer: a screening tool for primer-dimer and hairpin structures. Biotechniques 37: 226-231.

Vanderheyden N, Mai A, Gilissen A, Cassiman JJ, et al. (2007). Identification and sequence analysis of discordant phenotypes between AmpFISTR SGM Plus and PowerPlex 16. Int. J. Legal Med. 121: 297-301. http://dx.doi. org/10.1007/s00414-007-0167-5

Wang DY, Chang CW, Lagacé RE, Oldroyd NJ, et al. (2011). Development and validation of the AmpFISTR ${ }^{\circledR}$ Identifiler $^{\circledR}$ Direct PCR Amplification Kit: a multiplex assay for the direct amplification of single-source samples. J. Forensic Sci. 56: 835-845. http://dx.doi.org/10.1111/j.1556-4029.2011.01757.x

Wiegand P, Klein R, Braunschweiger G, Hohoff C, et al. (2006). Short amplicon STR multiplex for stain typing. Int. J. Legal Med. 120: 160-164. http://dx.doi.org/10.1007/s00414-005-0048-8

Zhang S, Bian Y, Tian H, Wang Z, et al. (2015). Development and validation of a new STR 25-plex typing system. Forensic Sci. Int. Genet. 17: 61-69. http://dx.doi.org/10.1016/j.fsigen.2015.03.008

\section{Supplementary material}

Table S1. Allelic frequency obtained for the 21 autosomal loci comprising the multiplex system.

Genetics and Molecular Research 16 (2): gmr16029557 